and electrolyte control has been much improved by the addition of new material. The section on artificial feeding of infants, by Evans and MacKeith, particularly delighted the reviewer for its clarity and simplicity, and the new chapter on endocrine disease, by D. V. Hubble, is very comprehensive, especially with regard to the many recent advances in this subject. Other sections that seemed worthy of special mention were those on the medical and surgical aspects of disease of the urinary tract, and Stanley Banks has again contributed his excellent section on infectious diseases. Finally a tribute should be paid to R. E. Bonham-Carter for putting congenital heart disease in the position that its importance merits with his comprehensive revision of the chapter dealing with this subject. One might quarrel, however, with his perpetuation of the fallacy that mitral stenosis occurs in 50 per cent. of cases of atrial septal defect.

There must inevitably be some criticisms in a book of this size, but they are remarkably few. It seems strange that the important subject of prematurity is dealt with in only six pages when the now rare but time-honoured subject of congenital syphilis gets 17 pages' notice. It is perhaps stranger that retrolental fibroplasia, acknowledged to be one of the commonest causes of blindness in children, is dealt with in only seven lines. Orie would have also thought that Dicke's important work on gluton-free diets in coeliac disease would have occurred sufficiently long ago to be able to include it in this edition. Finally, the reviewer would like to make a plea to the editors that the important subject of accidental poisoning in childhood merits a chapter in the next edition.

This is a much improved and expanded edition of this excellent textbook and is unreservedly commended to all with an interest in paediatrics.

J.D.L.R.

\section{SURGERY FOR STUDENTS OF NURSING}

By John Cairney, D.Sc., M.D., F.R.A.C.S. Pp. 326, with I 20 illustrations. Christchurch: N. M. Peryer Ltd. 1952. 40s.

An excellent book with an attractive title. ' Surgery for Students of Nursing' suggests that study is required in order to nurse intelligently.

The book is well planned. Basic principles are first laid down and study proceeds from the known to the unknown-for example, the septic finger is dealt with before more obscure infections such as tetanus or gas gangrene. The subject matter is presented concisely and the simplicity of the diagrams is a commendable feature of the book.

No student nurse reading the paragraph on the essential feature of shock could fail to follow the straightforward explanation.

Unfortunately the price, 40s., is beyond the financial resources of the majority of student nurses.. Although published in New Zealand, one or two copies should be included in every nurses' lending library, for such a textbook lends great support to classroom teaching.

$$
\text { M.A.L. }
$$

\section{PSYCHOSOMATIC MEDICINE}

By Franz Alexander, M.D. Pp. 300, with 5 illustrations. London: George Allen \& Unwin Ltd. I952. 2 Is.

The basic concepts on which the psychosomatic approach in medicine is founded and the existing knowledge about the influence of psychological factors upon the functions of the body and their disturbances, are presented with remarkable clarity by the author, who occupies the chair of psychiatry at the University of Illinois. According to the theory of specificity, physiological responses to emotional stimuli, both normal and morbid, vary according to the nature of the precipitating emotional state. The vegetative responses to different emotional stimuli vary also according to the quality of the emotions. Every emotional state has its own physiological syndrome. There is a distinct correlation between certain emotional constellations and certain vegetative innervations. Anxiety sets in motion different psychological chains, the nature of which is one factor determining the type of ensuing physiological response. Each person handles anxiety in a manner characteristic for him.

Chapters are devoted to the discussion of the specific emotional factors in gastro-intestinal disturbances; respiratory disturbances such as bronchial asthma; cardiovascular disturbances including essential hypertension; the emotional factors in skin diseases, in endocrine disturbances and in rheumatoid arthritis and other conditions of the joints and muscles.

In a final chapter on therapy, Prof. Alexander, having shown how the psychosomatic approach is based on specific knowledge of the emotional factors operating in every case and of those physiological mechanisms by which emotional factors influence the disease process, says that a general knowledge of pathology-both psychological and somatic-is the first basic requirement. Only after somatic and personality diagnoses have been made in close correlation with each other, can a treatment plan be formulated. Penetrating psychotherapeutic measures may precipitate transient exacerbations of somatic symptoms. Close co-operation between the psychiatrist and the medical specialist is imperative. The author, himself a leading psychoanalyst, goes so far as to say that in this era of psychosomatic medicine the lay psychotherapist as an independent practitioner will soon belong to the past.

Dr. Therese Benedek contributes a chapter on disturbances of the sexual functions. Her approach is perhaps too dogmatically psychoanalytical; for instance, she says that the fact that urethral eroticism is closely interwoven with infantile genital eroticism is responsible for the symptom of enuresis. Such a generalization seems improbable.

This book is an authoritative exposition of psychosomatic medicine, its principles and applications; it is relatively short, it reads easily and it merits careful study.

J.D.W.P. 